\title{
Perspectives on Resorbable Osteosynthesis Materials in Craniomaxillofacial Surgery
}

\author{
Paul Schumann ${ }^{\mathrm{a}}$ Daniel Lindhorst ${ }^{\mathrm{a}} \quad$ Maximilian E.H. Wagner ${ }^{\mathrm{a}} \quad$ Alexander Schramm $^{\mathrm{b}}$ \\ Nils-Claudius Gellrich ${ }^{\mathrm{a}}$ Martin Rücker ${ }^{\mathrm{a}}$ \\ ${ }^{a}$ Department of Oral and Maxillofacial Surgery, Hannover Medical School, Hannover, and bepartment of Oral and \\ Maxillofacial Surgery, German Federal Armed Forces Hospital, Ulm, Germany
}

\section{Key Words}

Craniomaxillofacial surgery · Osteosynthesis systems ·

Resorbable materials

\begin{abstract}
Since introduction to the clinics in the 1990s, resorbable osteosynthesis systems have undergone extensive improvements in order to establish their use as a standard treatment, especially in craniomaxillofacial surgery. However, the development of osteosynthesis systems made of poly(ahydroxy acid) polymers has been hindered by the lack of information on the mechanical properties and biocompatibility of these materials. Moreover, magnesium-based degredable osteosynthesis materials have not yet been integrated into clinical practice owing to biocompatibility problems. Osteosynthesis systems made from nonresorbable titanium alloys have shown excellent biocompatibility, stability and individual fitting to the implant bed, so these materials are currently considered the 'gold standard'. The procedure of plate removal has been subjected to intense scrutiny and controversy. Bioresorbable materials are indicated for special conditions, such as osteosynthesis of the growing skull or orbital floor reconstructions. This paper presents an overview of the currently available and investigated resorbable osteosynthesis materials in comparison with the nonre-
\end{abstract}

sorbable 'gold standard' titanium. The main problem areas such as sterilization, biocompatibility and stability are highlighted and perspectives for further improvements are provided.

Copyright ๑ 2013 S. Karger AG, Basel

\section{Background}

There is a great demand for osteosynthesis materials in craniomaxillofacial surgery. The most common facial fractures involving the mandible, zygoma and nasal bones are predominantly caused by car accidents, assaults and falls. Fractures of the maxilla and the mandible can lead to derangement of the occlusion, and thus, the mechanical load during mastication is often disproportionate to these relatively slim bony structures. Fractures and osteosynthesis materials are supported solely by a thin soft tissue layer. In addition, facial bones, particularly the zygoma and mandible, are characterized by a distinct threedimensional (3D) complexity compared to that of long bones. Besides traumas, osteosynthesis materials should meet the requirements of reconstructive surgery and corrective osteotomies not only in the adult but also in the adolescent skeleton. 
Internal fixation with suitable plates and screws following an open reduction is recognized to be the 'gold standard' for most facial fractures. The applied osteosynthesis materials have to be ductile and bendable for individual fitting. They should be as thin as possible to avoid visibility, palpability and exposure. On the other hand, they should also provide long-term stability according to the severity and type of facial fracture. Finally, osteosynthesis materials must also be biocompatible. Stainless steel, the cobalt alloy vitallium, chrome and molybdenum were applied until the mid-1980s; nowadays, titanium is used almost without exception for the osteosynthesis of craniomaxillofacial fractures concerning nonresorbable materials because of its excellent biomechanical characteristics. The disadvantages of using nonresorbable materials, especially those associated with the need to remove plates after fracture healing, have led to the development of biodegradable osteosynthesis systems, first applied in clinical settings in the 1990s. Currently, resorbable osteosyntheses are primarily generated from synthetic semicrystalline poly( $\alpha$-hydroxy acid) polymers and, more recently, degradable magnesium alloys have been introduced. It is nevertheless important to emphasize that the removal of asymptomatic plates and screws after fracture healing is still considered as an exceptionally controversial issue.

\section{Materials}

\section{Metals}

Stainless steel for surgical applications consists of iron, chrome and nickel. The main problem associated with the use of stainless steel in surgery is its limited resistance to corrosion. Corrosion products can be detected in the surrounding tissue [1] and these may often lead to hypersensitivity reactions among patients. Vitallium has also been associated with corrosion effects such as elevation [2] as well as the accumulation of metal ions in the blood. For these reasons, as well as the possible stress shielding effects and undesired deformations associated with corrosion, titanium is now used extensively in most surgical replacement procedures.

Titanium is currently considered the standard osteosynthesis material for the 3D reconstruction of craniomaxillofacial fractures for many reasons. It generally consists of alloys with variable amounts of aluminum, vanadium or niobium (standardized in ISO 5832-3).

In terms of its mechanical properties, titanium is highly stable despite its features of pliability and its light weight. Titanium has less elasticity than stainless steel or vitallium, and thus, the risk of stress shielding is unlikely. After implantation, a thin and insoluble layer of titanium oxide develops on the implant surface. Despite its unique feature of corrosion resistance, attributable to the titanium oxide layer, there is often a small amount of corrosion arising as a result of mechanical stress and friction between screws and plates [3].
In general, few toxic effects, which would be attributed to the presence of alloy additives, are associated with the use of titanium. Titanium particles can usually be observed in the scar tissue that covers the plates and in locoregional lymph nodes [4]. No clinically relevant toxic effects of aluminum ions and vanadium that dissolve out of the titanium-alloyed craniomaxillofacial osteosynthesis material have been reported thus far. Furthermore, no localized negative effects on the tissue surrounding the titanium implants (e.g. skeletal muscles) have been detected, and no allergic reactions or carcinogenic effects attributable to the use of titanium osteosynthesis materials have been reported to date [5].

The removal of titanium plates and screws requires precise differentiation between symptomatic and asymptomatic materials. If symptoms such as dislocation, bone atrophy by compression, palpability, thermal sensitivity, infection, wound dehiscence, foreign body response or extrusion occur, the osteosynthesis material needs to be removed. Apart from that, it is often advised that the nonresorbable material be removed from a growing skull due to the possibility of growth disturbance or even intracranial dislocation [6]. A general scheme for the removal of asymptomatic titanium osteosynthesis materials has not been established, although scientifically significant trials have been conducted. Unlike the practice in several European countries, asymptomatic plates and screws are not routinely removed in the USA and in the UK; this may be attributed to the cost of the removal procedure.

\section{Resorbable Osteosynthesis Material}

Although the performance and biocompatibility of metallic and titanium fixation in osteosynthesis has been reported as satisfactory, a number of disadvantages have been associated with its use, including stress shielding of bone or osteopenia [7], impairment in imaging evaluation [8], the need for surgical removal and its restricted use in certain specific circumstances such as pediatric craniofacial surgery [9]. Therefore, researchers during the 1960s engaged in the development of bioresorbable materials, namely poly $(\alpha$-hydroxy acid) polymers, which were designed to be stable enough for clinical application. Bioresorbable sutures were introduced to the market in the 1970s, followed by implants for internal bone fixation as well as bioresorbable polymers for the controlled release of drugs and proteins.

Bioresorbable polymers are mainly high-molecular-weight aliphatic polyesters with repeating units of a-hydroxy acid (HO$\mathrm{CHR}-\mathrm{COOH}$ ) derivatives manufactured by ring-opening polymerization [10]. The absorption of these polymers begins with depolymerization through the hydrolysis of their ester bonds and subsequent metabolism, probably by macrophages, in the citric acid cycle into water and carbon dioxide [11].

The first clinically used bioresorbable polymer was poly(glycolic acid) (PGA), a highly crystalline and high-molecular-weight molecule with limited clinical use for osteosynthesis because of its susceptibility to rapid degradation. Approximately 4-7 weeks after implantation, a duration which is insufficient to allow complete bone healing, PGA loses its mechanical strength in vivo [12]. In addition, the side effects of PGA have been detected during its clinical use; these are due to the difficulty in clearing the accumulated acid degradation products. These negative effects have resulted in the minimal use of pure PGA in osteosynthesis.

Poly(lactic acid) (PLA) is another high-molecular-weight bioresorbable polymer; its optically active carbon in lactic acid generates 2 stereoisomeric forms, namely poly-L-lactide (PLLA) and 
poly-D-lactide (PDLA). Since the early 1990s, PLLA has been used as an osteosynthesis material [13]. Due to its crystallinity and hydrophobicity, PLLA is fairly resistant to hydrolysis, and thus bioresorption with complete loss of its strength in vitro does not occur within the first 2 years of implantation. PDLA, on the other hand, has a lower crystallinity and is less resistant to hydrolysis. Because of its slower degradation rate, PDLA has been reported to be highly biocompatible [13], although crystalline particles resistant to degradation may elicit some inflammatory response.

By copolymerization of different derivatives of a-hydroxy acids, a variety of different mechanical qualities and degradation rates can be achieved. Copolymers of L-, D-lactides, for example, SR-P(L/DL)LA 70/30, a copolymer composed of 70\% PLLA and $30 \%$ PDLA, loses all its strength in vitro after 48 weeks of implantation [14]. Copolymers of L-lactide and glycolide (PLGA) have been extensively used owing to the wide range of physiochemical properties of the components. Vicryl ${ }^{\circledR}$ (Johnson \& Johnson) sutures are copolymers consisting of lactic acid and glycolic acid at a ratio of 8:92 and LactoSorb ${ }^{\circledR}$ (Biomet, Inc.) is composed of the same polymers in the nearly inverse ratio of $82: 18$; both these products are ideal for specific fields of application [15]. Because of their amorphous structure, copolymers do not release any crystalline particles and the rate of degradation is slow enough to facilitate high biocompatibility.

In contrast to metallic osteosynthesis, bioresorbable implants cannot be sterilized in the operating room through autoclaving. Manufacturers thus use either $\gamma$-irradiation or ethylene oxide gas (EtO) [16] for sterilization of implants.

Compared to titanium, the elasticity modulus of these polymers is below or as high as that of cortical bone, without the complication of stress shielding. Innovations such as the self-reinforced manufacturing technique improve the mechanical properties of bioresorbable polymers, resulting in a material that is almost equivalent to that of cortical bone [17] that allows plate molding in the operating room at ambient temperatures.

Further developments in improving the strength, rate of degradation and biocompatibility of these materials has resulted in the use of biodegradable osteosynthesis in a wide range of craniomaxillofacial procedures such as pediatric craniofacial surgery [18], mandibular fractures [19], fractures of the frontal sinus [20], maxillary osteotomies and sagittal split mandibular osteotomies [21].

Besides the osteosyntheses systems produced from poly $(\alpha-$ hydroxy acid) polymers, other aliphatic polyesters such as poly(pdioxanone) (PDS) and poly( $\varepsilon$-caprolactone) (PCL) have been developed and assessed. These materials are predominantly used in the production of biodegradable sutures; PDS is also used as an integral part of certain pins and orbital floor implants [22].

The use of magnesium for bone implants was first described by Lambotte in 1932 [23]. However, magnesium implants have been shown to have a high degradation rate, which often results in instability. In addition, the clinical use of pure magnesium implants has been associated with gas accumulation, causing subcutaneous gas gangrene [24]. The use of pure magnesium implants has thus decreased, especially after the introduction of stainless steel implants during the 1940s.

Modern methods in alloy composition have resulted in the production of magnesium alloys as key components of biomedical materials. Because corrosion of magnesium implants is essentially influenced by their elemental composition, alloys consisting of rare earth elements show a delay in corrosion, consequently ensur-

Resorbable Osteosynthesis Materials in

Craniomaxillofacial Surgery ing prolonged implant stability [25]. Compared to resorbable polymeric implant materials such as hydroxyapatite/PLLA, magnesium alloys show significantly higher yield strengths [26]. Witte et al. [26] demonstrated a total in vivo degradation of different magnesium alloys that contained either rare earth or aluminum and zinc. In addition, a significantly greater bone mass and a higher mineral apposition were observed during the degradation of magnesium alloy implants when compared to polymer materials. However, the biocompatibility of magnesium alloys needs to be further improved; it has been associated with gas production, leading to gangrene in animal models [26]. Sterilization of magnesium alloy implants is accomplished by $\gamma$-irradiation [26].

Magnesium alloys thus possess good mechanical stability, which provides total degradability, but their biocompatibility is questionable. Further research will be necessary to eliminate the risk of gas gangrene.

\section{Discussion}

Although the use of resorbable osteosynthesis materials in clinical settings presents several advantages, titanium is still considered the material of choice for osteosynthesis systems in craniomaxillofacial surgery. In particular, resorbables are not suitable if the osteosynthesis material has to fulfill contouring functions, e.g. in cases of midface reconstructions.

\section{Sterilization}

Because of their liability to high temperature and moisture, poly( $\alpha$-hydroxy acid) polymers cannot be sterilized by conventional steam sterilization. EtO sterilization and $\gamma$-irradiation are currently the methods of choice. Although EtO sterilization does not seem to impart any negative effects on the mechanical properties [27], a preconditioning phase may result in degradation. Additionally, gas residues with toxic or possibly carcinogenic potential may be produced by these polymers [28]. Structural changes caused by $\gamma$-irradiation can lead to major mechanical changes and polymer degradation [29].

The temperature for common dry sterilization procedures can be decreased by performing heat treatment in a dry atmosphere of an inert gas or vacuum, e.g. biodegradable pins can be sterilized under vacuum and/or argon for $1 \mathrm{~h}$ at $135^{\circ} \mathrm{C}$. Unfortunately, this method may result in modifications in mechanical properties, molecular weight and crystallinity [30]. Nonthermal plasma sterilization seems to be a very promising sterilization method. Various PLA polymers are completely sterilized after treatment with oxygen or carbon dioxide plasma. Interestingly, no major modifications in mechanical properties, molecular weight or crystallinity have been detected 
[31]. Autosterilization by injection molding for the sterilization of poly( $\alpha$-hydroxy acid) osteosynthesis materials has shown satisfactory results [32]; however, no further studies have been conducted.

No studies analyzing the effects of sterilization of magnesium alloy implants on the mechanical properties and the degradation process have been conducted to date.

\section{Biocompatibility}

Although osteosyntheses consisting of PLA and PGA have been considered highly biocompatible for decades, biocompatibility is regarded as a major concern in bioresorbable materials. Previous reports have identified various complications, including fistulas, osteolysis, soft tissue swelling, synovial inflammation and foreign body reactions [33]. Most of these complications are long-term sequelae [33]. The negative reactions to poly ( $\alpha$-hydroxy acid) polymers seem to be caused by the degradation process of the polymers [11] and subsequent changes in the tissue surrounding the materials. After EtO sterilization, toxic or possibly carcinogenic gas residues are emitted by these polymers, which could leak out as residual monomers or other additives. The process of degradation may cause a decrease in the $\mathrm{pH}$ level and a change in osmotic pressure. These incidents are most likely responsible for toxic responses [34]. Macrophages and fibroblasts are damaged [35], osteoblasts are affected, with the main impact on the bone remodeling process based on the amount of polymer particles [36]. The highly crystalline fragments and particles released by the disintegrating polymers could play a certain role for tumorigenesis [37]. Moreover, the surface texture of the implant, polymer additives, site of implantation and age of the patient can also influence the appearance and degree of incompatibility [38].

Several studies have been performed in an attempt to solve the problems concerning the biocompatibility of poly ( $\alpha$-hydroxy acid) polymers. The incorporation of basic salts could prevent a drop in the $\mathrm{pH}$ during the degradation process in vitro [39]. The bone remodeling process could be enhanced by loading biodegradable polymer implants with recombinant human fibroblast growth factor- 2 or transforming growth factor- $\beta$. However, the degradation process might be influenced by growth factors as well $[40,41]$. Linking implants with monoclonal antibodies to interferon- $\gamma$ (IFN- $\gamma$ ) leads to a delayed activation of macrophages and foreign body giant cells [42]. Another approach to stabilize the $\mathrm{pH}$ during degradation is to regulate the molecular weight distribution of the polymer. It has been shown that the rate of lactic acid re- lease of PLA is commensurate to the quantity of low-molecular-weight components in the polymer [43]. Rapid degradation techniques have been developed to examine the degradation characteristics of poly(a-hydroxy acid) polymers, thereby allowing the analysis of particles generated during degradation. These studies are of special interest because they provide details on the relationship of toxic effects and polymer particles [36].

Although biodegredable magnesium stents have been successfully established for coronary arteries, magnesium alloy-based bone implants or osteosynthesis materials for clinical use do not currently exist. Biocompatibility problems are generally associated with excessive gas formation [44] and adverse host reactions such as osteoclastdriven bone resorption or the subsequent periosteal formation of new bone [45].

\section{Stability}

Several comparative studies on titanium and resorbable fixation systems containing poly( $\alpha$-hydroxy acid) polymers have been performed in the field of craniomaxillofacial surgery. Most of these studies were conducted in vitro and involve the mandible, such as mandibulotomies, mandible angle fractures and orthognathic surgeries [46-48]. These studies have shown that the mechanical properties of titanium are superior to those of resorbable materials. Biodegradable osteosyntheses thus need to be larger and bulkier to compensate for lack in strength and rigidity. However, resorbables should consist of very little material to demonstrate their main advantage of innocuous implant degradation.

Different approaches have been undertaken to improve the mechanical properties of resorbable materials. Techniques such as self-reinforced manufacturing [17] and solid-state extrusion [49] have been introduced to obtain fibrillar orientation, which leads to improved bending and shear strength. To overcome the brittleness of polymers under tensile and bending loads, blending with biodegradable rubbers has been performed with several promising results [50].

The lesser tensile strengths of resorbable polymers compared to titanium have direct consequences for clinical practice. Threads have to be tapped because self-tapping screws do not exist. If screws do not fit exactly, it is possible that friction force may break them. 'Ultrasonic bone welding' may solve this problem. Pins instead of screws are liquefied using ultrasound energy and subsequently pressed into the Harversian canals. After resolidification, an intense and reinforced implant-bone compound is generated [51]. Another clinical problem 
Fig. 1. Cranioplasty of a pediatric craniosynostosis patient. Resorbable osteosynthesis material is marked with arrows.
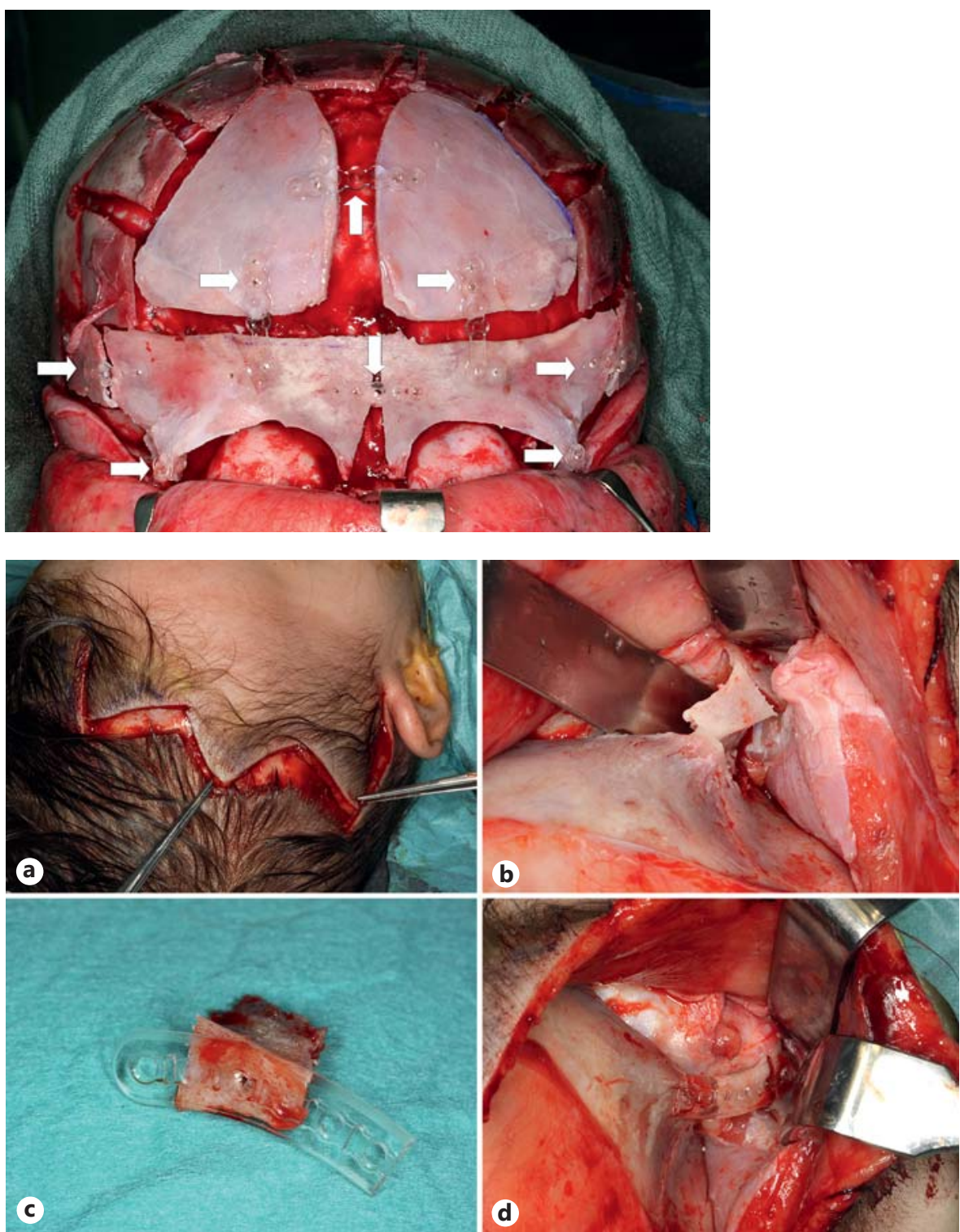

Fig. 2. Intraorbital tumor resection of a pediatric patient. a Hemicoronal approach. b Osteotomy of the lateroorbital rim. c Extracorporeal preparation of the lateroorbital rim before reposition: fixation with a resorbable plate and screw. d Reposition and osteosynthesis.

\section{Clinical Significance}

A main advantage of resorbable osteosynthesis matePlates generally consist of poly( $\alpha$-hydroxy acid) polymers and thus may also be bent at a temperature of approximately $60^{\circ} \mathrm{C}$. Because of their thermolabile nature, unregulated heating can affect the molecular structure and, consequently, its stability and degradation [51]. In addition, the production (injection molding) and sterilization processes can influence stability [52].

Current publications indicate that the mechanical properties of magnesium alloy implants are satisfactory. They not only achieve enhanced bone response but also excellent interfacial and compressive strength. Therefore they seem to be extremely suitable for load-bearing applications [53]. rial is the fact that a removal is not necessary. In contrast to clinical practices in Europe, metallic asymptomatic osteosynthesis material is not routinely removed in the USA and the UK. Therefore, metallic asymptomatic material may be left intracorporeally. Nevertheless, symptomatic metallic material has to be removed. In these cases, resorbable osteosynthesis materials, especially poly $(\alpha-$ hydroxy acid) polymers, could be an applicable alternative. Apart from problems concerning sterilization and molding, poly( $\alpha$-hydroxy acid) polymers are usually not stable enough for load-bearing applications. For this rea- 
son, they are not suitable for osteosyntheses of the mandible. They may be inserted in the midface, but only for small defects and if contouring functions are not demanded. Studies have shown that particularly for the reconstruction of extensive orbital floor fractures, PDS is not adequate. To achieve an anatomically correct sagittal and vertical long-term 3D reconstruction of the orbital floor, nonresorbable materials such as individualized titanium implants have to be used. It has been demonstrated that only in this way a physiological bulb position is possible and enophthalmos and hypophthalmos can be avoided [54]. For osteosyntheses of the neurocranium, poly( $\alpha$-hydroxy acid) polymers are applicable, especially for cranioplasties for pediatric craniosynostosis patients (fig. 1) [18]. Although the possibility of growth distur- bance using nonresorbable material is not terminally proven [55], resorbables are routinely used for surgical interventions of the growing skull if plate removal might be complicated due to possible nerve damage or extensive soft tissue detachment (fig. 2).

Finally, the literature shows that resorbable osteosynthesis materials do not fulfill the requirements to replace titanium in craniomaxillofacial surgery or other surgical fields at present. Recent studies have shown that degradable magnesium alloy implants may overcome the stability problems of poly( $\alpha$-hydroxy acid) polymers [53]. Therefore, further intensive research has to be performed to solve the biocompatibility problems of magnesium alloy implants.

\section{References}

$\checkmark 1$ Moberg LE, Nordenram A, Kjellman O: Metal release from plates used in jaw fracture treatment. A pilot study. Int J Oral Maxillofac Surg 1989;18:311-314.

2 Woodman JL, Black J, Nunamaker DM: Release of cobalt and nickel from a new total finger joint prosthesis made of vitallium. J Biomed Mater Res 1983;17:655-668.

-3 Solar RJ, Pollack SR, Korostoff E: In vitro corrosion testing of titanium surgical implant alloys: an approach to understanding titanium release from implants. J Biomed Mater Res 1979; 13:217-250.

-4 Case CP, Langkamer VG, James C, Palmer MR, Kemp AJ, Heap PF, Solomon L: Widespread dissemination of metal debris from implants. J Bone Joint Surg Br 1994;76:701712 .

5 Lewis CG, Belniak RM, Plowman MC, Hopfer SM, Knight JA, Sunderman FW Jr: Intraarticular carcinogenesis bioassays of CoCrMo and TiALV alloys in rats. J Arthroplasty 1995; 10:75-82.

6 Yu JC, Bartlett SP, Goldberg DS, Gannon F, Hunter J, Habecker P, Whitaker LA: An experimental study of the effects of craniofacial growth on the long-term positional stability of microfixation. J Craniofac Surg 1996;7:64-68.

7 Paavolainen P, Karaharju E, Slatis P, Ahonen J, Holmstrom T: Effect of rigid plate fixation on structure and mineral content of cortical bone. Clin Orthop Relat Res 1978;136:287293.

8 Fiala TG, Novelline RA, Yaremchuk MJ: Comparison of CT imaging artifacts from craniomaxillofacial internal fixation devices. Plast Reconstr Surg 1993;92:1227-1232.

-9 Orringer JS, Barcelona V, Buchman SR: Reasons for removal of rigid internal fixation devices in craniofacial surgery. J Craniofac Surg 1998;9:40-44.
10 Hastings GW, Ducheyne P: Macromolecular Biomaterials. Boca Raton, CRC Press, 1984.

11 Pietrzak WS: Principles of development and use of absorbable internal fixation. Tissue Eng 2000;6:425-433.

12 Vasenius J, Vainionpaa S, Vihtonen K, Makela A, Rokkanen P, Mero M, Tormala P: Comparison of in vitro hydrolysis, subcutaneous and intramedullary implantation to evaluate the strength retention of absorbable osteosynthesis implants. Biomaterials 1990;11:501504.

13 Pihlajamaki H, Bostman O, Hirvensalo E, Tormala P, Rokkanen P: Absorbable pins of self-reinforced poly-L-lactic acid for fixation of fractures and osteotomies. J Bone Joint Surg Br 1992;74:853-857.

14 Tormala P, Pohjonen T, Rokkanen P: Bioabsorbable polymers: Materials technology and surgical applications. Proc Inst Mech Eng $\mathrm{H}$ 1998;212:101-111.

15 Pietrzak WS, Kumar M: An enhanced strength retention poly(glycolic acid)-poly(Llactic acid) copolymer for internal fixation: in vitro characterization of hydrolysis. J Craniofac Surg 2009;20:1533-1537.

16 Nuutinen JP, Clerc C, Virta T, Tormala P: Effect of gamma, ethylene oxide, electron beam, and plasma sterilization on the behaviour of SR-PLLA fibres in vitro. J Biomater Sci Polym Ed 2002;13:1325-1336.

17 Joukainen A, Pihlajamaki H, Makela EA, Ashammakhi N, Viljanen J, Patiala H, Kellomaki M, Tormala P, Rokkanen P: Strength retention of self-reinforced drawn poly-L/DL-lactide 70/30 (SR-PLA70) rods and fixation properties of distal femoral osteotomies with these rods. An experimental study on rats. J Biomater Sci Polym Ed 2000;11:1411-1428.
18 Ahmad N, Lyles J, Panchal J, Deschamps-Braly J: Outcomes and complications based on experience with resorbable plates in pediatric craniosynostosis patients. J Craniofac Surg 2008;19:855-860.

19 Agarwal S, Gupta A, Grevious M, Reid RR: Use of resorbable implants for mandibular fixation: a systematic review. J Craniofac Surg 2009;20:331-339.

$20 \mathrm{Kim} \mathrm{CH}$, Kim DH, Kim da H, Song SY: Treatment of frontal sinus fracture using bioabsorbable mesh plates. J Craniofac Surg 2012; 23:549-551.

21 Fedorowicz Z, Nasser M, Newton JT, Oliver RJ: Resorbable versus titanium plates for orthognathic surgery. Cochrane Database Syst Rev 2007:CD006204.

22 Iizuka T, Mikkonen P, Paukku P, Lindqvist C: Reconstruction of orbital floor with polydioxanone plate. Int J Oral Maxillofac Surg 1991; 20:83-87.

23 Lambotte A: L'utilisation du magnesium comme materiel perdu dans l'osteosynthèse. Bull Mém Soc Nat Chir 1932;28:1325-1334.

24 McCord C: Chemical gas gangrene from metallic magnesium. Ind Med 1942;11:71-79.

25 Gröbner J, Kervokrkov D, Schmidt-Fetzer R, Bach F-W, Haferkamp H, Jaschik C: Materials Design Approaches and Experiences. TMS Symposium, Indianapolis, 2001.

26 Witte F, Kaese V, Haferkamp H, Switzer E, Meyer-Lindenberg A, Wirth CJ, Windhagen $\mathrm{H}$ : In vivo corrosion of four magnesium alloys and the associated bone response. Biomaterials 2005;26:3557-3563.

27 Pietrzak WS: Effects of ethylene oxide sterilization on 82:18 PLLA/PGA copolymer craniofacial fixation plates. J Craniofac Surg 2010;21:177-181. 
28 Hagmar L, Mikoczy Z, Welinder H: Cancer incidence in Swedish sterilant workers exposed to ethylene oxide. Occup Environ Med 1995;52:154-156.

29 Skiens WE: Sterilizing effects on selected polymers. Radiat Phys Chem 1980;5:47.

30 Gogolewski S, Mainil-Varlet P: The effect of thermal treatment on sterility, molecular and mechanical properties of various polylactides. I. Poly(L-lactide). Biomaterials 1996;17:523528.

31 Gogolewski S, Mainil-Varlet P, Dillon JG: Sterility, mechanical properties, and molecular stability of polylactide internal-fixation devices treated with low-temperature plasmas. J Biomed Mater Res 1996;32:227-235.

-32 Konig C, Ruffieux K, Wintermantel E, Blaser $\mathrm{J}$ : Autosterilization of biodegradable implants by injection molding process. J Biomed Mater Res 1997;38:115-119.

-33 Bergsma EJ, Rozema FR, Bos RR, de Bruijn WC: Foreign body reactions to resorbable poly(L-lactide) bone plates and screws used for the fixation of unstable zygomatic fractures. J Oral Maxillofac Surg 1993;51:666670.

34 Ignatius AA, Claes LE: In vitro biocompatibility of bioresorbable polymers: Poly(L, DL-lactide) and poly(L-lactide-co-glycolide). Biomaterials 1996;17:831-839.

- 35 Saad B, Ciardelli G, Matter S, Welti M, Uhlschmid GK, Neuenschwander P, Suter UW: Characterization of the cell response of cultured macrophages and fibroblasts to particles of short-chain poly[(r)-3-hydroxybutyric acid]. J Biomed Mater Res 1996;30:429429.

36 Wake MC, Gerecht PD, Lu L, Mikos AG: Ef fects of biodegradable polymer particles on rat marrow-derived stromal osteoblasts in vitro. Biomaterials 1998;19:1255-1268.

37 Nakamura T, Shimizu Y, Okumura N, Matsui T, Hyon SH, Shimamoto T: Tumorigenicity of poly-L-lactide (PLLA) plates compared with medical-grade polyethylene. J Biomed Mater Res 1994;28:17-25.
Bhatia S, Shalaby SW, Powers DL, Lancaster RL, Ferguson RL: The effect of site of implantation and animal age on properties of polydioxanone pins. J Biomater Sci Polym Ed 1994;6:435-446.

39 Agrawal CM, Athanasiou KA: Technique to control $\mathrm{pH}$ in vicinity of biodegrading PLAPGA implants. J Biomed Mater Res 1997;38: 105-114.

40 Winet H, Bao JY: Fibroblast growth factor-2 alters the effect of eroding polylactide-polyglycolide on osteogenesis in the bone chamber. J Biomed Mater Res 1998;40:567-576.

41 Tieline L, Puolakkainen P, Pohjonen T, Rautavuori J, Tormala P, Rokkanen P: The effect of transforming growth factor-beta1, released from a bioabsorbable self-reinforced polylactide pin, on a bone defect. Biomaterials 2002; 23:3817-3823.

-42 Khouw IM, van Wachem PB, de Leij LF, van Luyn MJ: Inhibition of the tissue reaction to a biodegradable biomaterial by monoclonal antibodies to IFN-gamma. J Biomed Mater Res 1998;41:202-210.

43 von Recum HA, Cleek RL, Eskin SG, Mikos AG: Degradation of polydispersed poly(L-lactic acid) to modulate lactic acid release. Biomaterials 1995;16:441-447.

44 Kraus T, Fischerauer SF, Hanzi AC, Uggowitzer PJ, Loffler JF, Weinberg AM: Magnesium alloys for temporary implants in osteosynthesis: in vivo studies of their degradation and interaction with bone. Acta Biomater 2012;8: 1230-1238.

45 Huehnerschulte TA, Reifenrath J, von Rechenberg B, Dziuba D, Seitz JM, Bormann $D$, Windhagen $\mathrm{H}$, Meyer-Lindenberg A: In vivo assessment of the host reactions to the biodegradation of the two novel magnesium alloys ZEK100 and AX30 in an animal model. Biomed Eng Online 2012;11:14.
46 Ricalde P, Engroff SL, Von Fraunhofer JA, Posnick JC: Strength analysis of titanium and resorbable internal fixation in a mandibulotomy model. J Oral Maxillofac Surg 2005;63: 1180-1183.

47 Ahn YS, Kim SG, Baik SM, Kim BO, Kim HK, Moon SY, Lim SH, Kim YK, Yun PY, Son JS: Comparative study between resorbable and nonresorbable plates in orthognathic surgery. J Oral Maxillofac Surg 2010;68:287-292.

48 Bregagnolo LA, Bertelli PF, Ribeiro MC, Sverzut CE, Trivellato AE: Evaluation of in vitro resistance of titanium and resorbable (poly-LDL-lactic acid) fixation systems on the mandibular angle fracture. Int J Oral Maxillofac Surg 2011;40:316-321.

49 Weiler W, Gogolewski S: Enhancement of the mechanical properties of polylactides by solid-state extrusion. I. Poly(D-lactide). Biomaterials 1996;17:529-535.

50 Grijpma DW, Hofslot RDA, Super H, Nijenhuis AJ, Pennings AJ: Rubber toughening of poly(L-lactide) by blending and block copolymerization. Polym Eng Sci 1994;34:1674.

51 Neumann A, Kevenhoerster K: Biomaterials for craniofacial reconstruction. GMS Curr Top Otorhinolaryngol Head Neck Surg 2009; 8:Doc08.

52 Gogolewski S: Bioresorbable polymers in trauma and bone surgery. Injury 2000; 31(suppl 4):28-32.

53 Li Y, Wen C, Mushahary D, Sravanthi R, Harishankar N, Pande G, Hodgson P: Mg-Zr-Sr alloys as biodegradable implant materials. Acta Biomater 2012;8:3177-3188.

54 Kokemüller H, von See C, Essig H, Tavassol F, Rucker M, Schramm A, Majdani O, Gellrich NC: Reconstruction of complex midfacial defects with individualized titanium implants. HNO 2011;59:319-326.

55 Kovacs AF, Sauer SN, Stefenelli U, Klein C: Growth of the orbit after frontoorbital advancement using nonrigid suture vs. rigid plate fixation technique. J Pediatr Surg 2008; 43:2075-2081.
Resorbable Osteosynthesis Materials in Craniomaxillofacial Surgery 